\title{
Accurate Adaptive Compensation Method for Mechanical Structure Error of the Blade Measuring System
}

\author{
Wei Shao ${ }^{(D)},{ }^{1}$ Peng Peng, ${ }^{1}$ Awei Zhou, ${ }^{2}$ Quanquan Zhu, ${ }^{1}$ and Di Zhao ${ }^{1}$ \\ ${ }^{1}$ Xi'an University of Technology, College of Mechanical and Precision Instrument Engineering, Xian 710048, China \\ ${ }^{2}$ Xian Polytechnic University, School of Mechanical and Electronic Engineering, Xian 710048, China \\ Correspondence should be addressed to Wei Shao; swlxm@163.com
}

Received 14 May 2018; Revised 25 September 2018; Accepted 30 September 2018; Published 17 October 2018

Academic Editor: Alberto Borboni

Copyright (c) 2018 Wei Shao et al. This is an open access article distributed under the Creative Commons Attribution License, which permits unrestricted use, distribution, and reproduction in any medium, provided the original work is properly cited.

\begin{abstract}
In view of the high precision requirement for mechanical structure of aeronautical blade measuring system, this paper proposes a laser interferometer to measure the error of the spatial nodes of the measuring system based on a comprehensive analysis of domestic and foreign error compensation methods for the measuring system. The optimized algorithm backpropagation (BP) neural network (OA-BPNN) compensation method is utilized to adaptively compensate for the systematic error of the mechanical system. Compared with the traditional polynomial fitting and genetic algorithm BP neural network (GA-BPNN) algorithm, the results show that the OA-BPNN algorithm is characterized by the best adaptability, precision, and efficiency for the adaptive error compensation. The spatial errors in the XYZ directions are reduced from 10.9, 60.1, and $84.2 \mu \mathrm{m}$ to 1.3, 4.0, and 2.4 $\mu \mathrm{m}$, respectively. The method is of great theoretical significance and practical value.
\end{abstract}

\section{Introduction}

As the blade is one of the essential components of the engine, the measurement of the blade with high efficiency, precision, and consistency in the manufacturing process is fundamental to enhance the manufacturing quality $[1,2]$. At present, the blade measuring system with the coordinate measuring machine as the main part finds wide use. However, in the measurement process, it is difficult to achieve the high precision required for blade measurement [3-5], which is mainly due to the fact that the mechanical structure error of the measuring machine increases the measurement error [6]. The error compensation is an effective method to improve the overall accuracy of the measuring machine[7]. Therefore, in order to improve the accuracy of the blade measuring system, it is important to compensate for the mechanical structural error of the measuring system.

The error of the mechanical system mainly includes geometric error, force deformation error, thermal error, and dynamic error $[8,9]$. These deformations change the spatial position of the measuring head, causing error in the data and affecting the accuracy of the measuring system. Thermal error is caused by the deformation of the mechanism due to temperature changes or temperature differences at different locations $[10,11]$. The dynamic error results from the dynamic deformation and vibration of the mechanical structural components due to the inertial force caused by the different speeds of the mechanism during the measurement process [12]. The blade measuring system in this paper realizes blade measurement by using the cone-optical polarization holography technology and the cylindrical coordinate mechanical structure [13]. The heat source is small and the environment temperature is constant, so the thermal error is small. The turntable rotates and the measuring head follows in the measurement, so the dynamic error is small. As a result, mainly geometric error and force deformation error influence the system accuracy.

Many experts and scholars have studied the compensation for the error of the mechanical structure of the measurement system. R. Hocken [14] expressed the single error of the mechanical structure with a fitting polynomial, which can obviously improve the measurement accuracy of the measuring system. However, the error models of different machines are different, so this method is not adaptive. Guo 


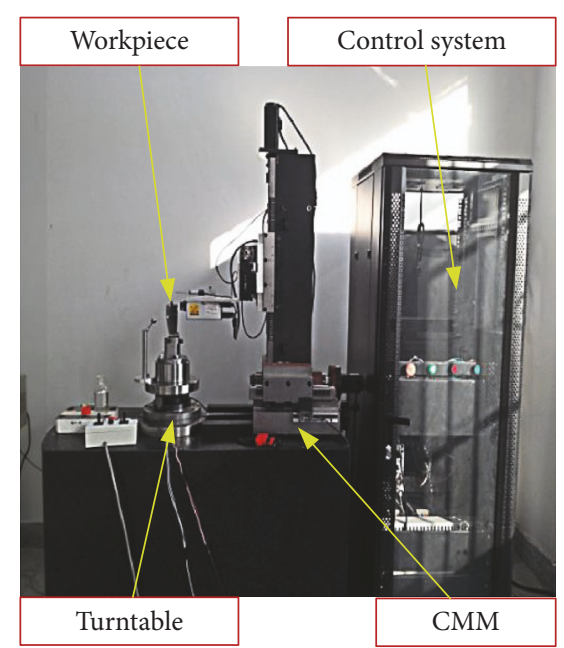

FIgURe 1: Photo of the blade measuring system.

Junjie et al. [15] analyzed the spatial error of the mechanical structure of the measuring system and proposed an algorithm for separating 21 geometric errors. Lin Shuwen et al. [16]. used the coordinate kinematic chain method for system analysis to compensate for the error of the entire system based on the kinematic chain of the space coordinate system. Literature [17-21] deals with geometric error and force deformation error of the measuring machine based on meshing [17-21]. The above methods compensate for error by least square or cubic interpolation, so the accuracy of compensation is easily affected by the different mechanical structures and the mesh spacing.

In this paper, based on previous research, the laser interferometer is used to measure the error of the spatial nodes of the mechanical structure, and the optimized backpropagation neural network (OA-BPNN) algorithm is applied to adaptively compensate for the error. Compared with the polynomial fitting and genetic backpropagation neural network (GA-BPNN) algorithm, the OA-BPNN algorithm boasts best adaptability, precision, and efficiency for the adaptive error compensation. The method is of great theoretical significance and practical value.

\section{Error Analysis of the Blade Measuring System}

The blade measuring system designed in this paper is shown in Figure 1. The system, with the cylindrical coordinate measuring machine as the main part, is mainly composed of three linear axes, a rotation axis, a grating scale, and a drive device. To enhance the measurement accuracy of the system, it is necessary to analyze the mechanical structure and establish the corresponding mathematical model of the structure [22]. As shown in Figure 2, assuming that the system workbench and each axis are ideal rigid bodies with constant state during the measurement process, the basic coordinate system XYZ is established on the workbench. The coordinate system $\mathrm{X}_{1} \mathrm{Y}_{1} \mathrm{Z}_{1}$ translated along the $\mathrm{Y}$-axis is established at the $\mathrm{Y}$-axis origin; the coordinate system $\mathrm{X}_{2} \mathrm{Y}_{2} \mathrm{Z}_{2}$

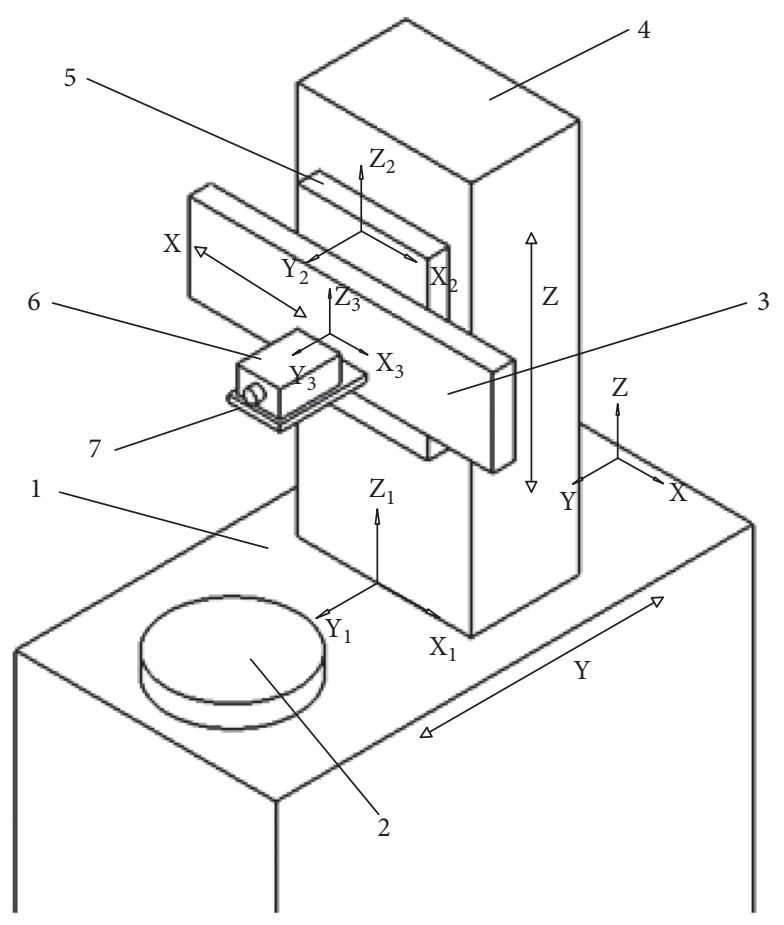

FIGURE 2: Simplified coordinate system of the measuring machine. (1) Workbench. (2) Rotary table. (3) X-axis slider. (4) Z-axis column. (5) Z-axis slider. (6) Measuring head. (7) Support of the measuring head.

translated along the $\mathrm{X}$-axis is established at the $\mathrm{X}$-axis origin; the coordinate system $\mathrm{X}_{3} \mathrm{Y}_{3} \mathrm{Z}_{3}$ translated along the $\mathrm{Z}$-axis is established at the $\mathrm{Z}$-axis origin.

In the measurement process, the measuring head in the position $\mathrm{M}\left(\mathrm{x}_{\mathrm{m}}, \mathrm{y}_{\mathrm{m}}, \mathrm{z}_{\mathrm{m}}\right)$ in the basic coordinate system moves by $\mathrm{x}, \mathrm{y}, \mathrm{z}$ along the $\mathrm{X}-, \mathrm{Y}-, \mathrm{Z}$-axes to the new point $\mathrm{N}\left(\mathrm{x}_{\mathrm{n}}\right.$, $\mathrm{y}_{\mathrm{n}}, \mathrm{z}_{\mathrm{n}}$ ) when the measuring machine moves. At this time, the coordinates of point $\mathrm{N}$ are $\left(\mathrm{x}+\mathrm{x}_{\mathrm{m}}, \mathrm{y}+\mathrm{y}_{\mathrm{m}}, \mathrm{z}+\mathrm{z}_{\mathrm{m}}\right)$, but in reality, its position is affected by the motion error and the deformation of the measuring machine. As a result, the theoretical coordinates of the $\mathrm{N}$ point of the measuring head are $\left(x+x_{m}, y+y_{m}, z+z_{m}\right)$ and the actual coordinates are $\left(x_{n}\right.$, $\left.y_{n}, z_{n}\right)$, so the difference between the actual value and the theoretical value is the measurement error.

Therefore, during the measurement process, after a point in the local coordinate system $\mathrm{X}_{1} \mathrm{Y}_{1} \mathrm{Z}_{1}$ has moved by $\mathrm{y}$ in the $\mathrm{Y}$ direction, the coordinates of origin $\mathrm{O} 1$ in the coordinate system XYZ can be represented by the following vector:

$$
O O_{1}=Y=\left(\begin{array}{c}
\delta_{x}(y) \\
y+\delta_{y}(y) \\
\delta_{z}(y)
\end{array}\right)
$$

In the above formula, $\delta_{x}(y), \delta_{y}(y), \delta_{z}(y)$ are the positioning errors in the $\mathrm{X}, \mathrm{Y}, \mathrm{Z}$ directions, respectively.

At the same time, theoretically, the coordinate system $\mathrm{X}_{1} \mathrm{Y}_{1} \mathrm{Z}_{1}$ has a rotation angle error with respect to XYZ. Assuming that the coordinate system XYZ rotates by the angles $\theta, \varphi$, and $\omega$ around $\mathrm{Z}, \mathrm{Y}$, and $\mathrm{X}$ axes, respectively, the 
relationship between the two local coordinate systems can be presented by the rotation matrix $\mathrm{R}$ :

$$
\left[\begin{array}{l}
x_{1} \\
y_{1} \\
z_{1}
\end{array}\right]=R\left[\begin{array}{l}
x \\
y \\
z
\end{array}\right]
$$

The rotation matrix $\mathrm{R}$ is a trigonometric function matrix involving the three angles, and the relationship matrix is as follows:

$R$

$$
=\left[\begin{array}{ccc}
\cos \theta & \sin \theta & 0 \\
-\sin \theta & \cos \theta & 0 \\
0 & 0 & 1
\end{array}\right]\left[\begin{array}{ccc}
\cos \varphi & 0 & -\sin \varphi \\
0 & 1 & 0 \\
\sin \varphi & 0 & \cos \varphi
\end{array}\right]\left[\begin{array}{ccc}
1 & 0 & 0 \\
0 & \cos \omega & \sin \omega \\
0 & -\sin \omega & \cos \omega
\end{array}\right]
$$

In the above relationship, since the angular error is very small during the actual movement, the matric involving the three angles can be simplified as follows:

$$
\begin{aligned}
R & =\left[\begin{array}{ccc}
\theta & \theta & 0 \\
-\theta & \theta & 0 \\
0 & 0 & 1
\end{array}\right]\left[\begin{array}{ccc}
\varphi & 0 & -\varphi \\
0 & 1 & 0 \\
\varphi & 0 & \varphi
\end{array}\right]\left[\begin{array}{ccc}
1 & 0 & 0 \\
0 & \omega & \omega \\
0 & -\omega & \omega
\end{array}\right] \\
& =\left[\begin{array}{ccc}
1 & \theta & -\varphi \\
-\theta & 1 & \omega \\
\varphi & -\omega & 1
\end{array}\right]
\end{aligned}
$$

The three angles $\theta, \varphi$, and $\omega$ are angular motion errors $\varepsilon_{\mathrm{Z}}(\mathrm{y}), \varepsilon_{\mathrm{y}}(\mathrm{y})$, and $\varepsilon_{\mathrm{x}}(\mathrm{y})$, respectively, and the rotation matrix caused by the movement in the $\mathrm{Y}$ direction can be represented by $\mathrm{R}(\mathrm{y})$ as follows:

$$
R(y)=\left[\begin{array}{ccc}
1 & \varepsilon_{z}(y) & -\varepsilon_{y}(y) \\
-\varepsilon_{z}(y) & 1 & \varepsilon_{x}(y) \\
\varepsilon_{y}(y) & -\varepsilon_{x}(y) & 1
\end{array}\right]
$$

Similarly, the relationship of the coordinate change of the coordinate system in the $\mathrm{Z}$ direction can be obtained as follows:

$$
\mathrm{O}_{1} \mathrm{O}_{2}=\mathrm{Z}=\left[\begin{array}{c}
\varepsilon_{x}(z) \\
\varepsilon_{y}(z)-z \alpha_{y z} \\
z+\varepsilon_{z}(z)
\end{array}\right]
$$

The rotation matrix can be obtained:

$$
R(z)=\left[\begin{array}{ccc}
1 & \varepsilon_{z}(z) & -\varepsilon_{y}(z) \\
-\varepsilon_{z}(z) & 1 & \varepsilon_{x}(z) \\
\varepsilon_{y}(z) & -\varepsilon_{x}(z) & 1
\end{array}\right]
$$

Similarly, the relationship of the coordinate change of the coordinate system in the X direction can be obtained as follows:

$$
\mathrm{O}_{2} \mathrm{O}_{3}=\mathrm{X}=\left[\begin{array}{c}
x+\varepsilon_{x}(x) \\
\varepsilon_{y}(x)-y \alpha_{x y} \\
\varepsilon_{z}(x)-z \alpha_{x z}
\end{array}\right]
$$

The rotation matrix can be obtained:

$$
R(x)=\left[\begin{array}{ccc}
1 & \varepsilon_{z}(x) & -\varepsilon_{y}(x) \\
-\varepsilon_{z}(x) & 1 & \varepsilon_{x}(x) \\
\varepsilon_{y}(x) & -\varepsilon_{x}(x) & 1
\end{array}\right]
$$

In the coordinate system XYZ, the measuring head moves from $M$ to $N$, and the coordinates of point $N$ on the head are $\left(X_{n}, Y_{n}, Z_{n}\right)$. The position of $M$ in the $X_{3} Y_{3} Z_{3}$ coordinate system can be represented by $\mathrm{O}_{3} \mathrm{M}\left(\mathrm{x}_{\mathrm{m}}, \mathrm{y}_{\mathrm{m}}, \mathrm{z}_{\mathrm{m}}\right)$. The point is transformed into a point in the coordinate system $\mathrm{X}_{2} \mathrm{Y}_{2} \mathrm{Z}_{2}$, and so the coordinates of point $\mathrm{M}$ in the coordinate system $\mathrm{X}_{2} \mathrm{Y}_{2} \mathrm{Z}_{2}$ can be obtained as follows:

$$
\mathrm{O}_{2} \mathrm{M}=\mathrm{O}_{2} \mathrm{O}_{3}=R^{-1}(x) \mathrm{O}_{3} \mathrm{M}
$$

The point $M$ is transformed from the coordinate system $\mathrm{X}_{2} \mathrm{Y}_{2} \mathrm{Z}_{2}$ into the coordinate system $\mathrm{X}_{1} \mathrm{Y}_{1} \mathrm{Z}_{1}$, and then the coordinates of point $\mathrm{M}$ in the coordinate system $\mathrm{X}_{1} \mathrm{Y}_{1} \mathrm{Z}_{1}$ are obtained:

$$
O_{1} M=O_{1} O_{2}=R^{-1}(z) O_{2} M
$$

The OM is the position of point M in the XYZ system; the coordinates of OM are

$$
O M=O O_{1}=R^{-1}(y) O_{1} M
$$

At this time, point $\mathrm{M}$ is point $\mathrm{N}$ that moves to this point, so the following equation can be derived:

$$
O N=O M+\Delta \delta
$$

The equation can be organized to find the coordinates of point $\mathrm{N}$ :

$$
\begin{array}{r}
O N=O O_{1}+R^{-1}(x) O_{1} M+\Delta \delta=O O_{1}+R^{-1}(x) \\
\cdot\left[O_{1} O_{2}+R^{-1}(z)\left(O_{2} O_{3}+R^{-1}(x) O_{3} M\right)\right]+\Delta \delta
\end{array}
$$

$\Delta \delta$ is an additional term due to complex reasons. The additional term, which is a complex deformation caused by uncertain factors in the measurement process, exists theoretically but cannot be described by certain mathematical formulas and numerical values.

$$
\Delta \delta=\left[\begin{array}{c}
\delta_{x}(x, z), \varepsilon_{x}(x, z) \\
\delta_{y}(y, z), \varepsilon_{y}(y, z) \\
\delta_{z}(x, z), \delta_{z}(y, z)
\end{array}\right]
$$


Substitution of the above equations into the calculation equation $\mathrm{ON}$ and the expansion of the equation yields a threedimensional matrix expression about $\mathrm{ON}$ :

$$
\begin{aligned}
& \mathrm{ON}=\left(\begin{array}{c}
\delta_{x}(y) \\
y+\delta_{y}(y) \\
\delta_{z}(y)
\end{array}\right)+\left[\begin{array}{ccc}
1 & \varepsilon_{z}(y) & -\varepsilon_{y}(y) \\
-\varepsilon_{z}(y) & 1 & \varepsilon_{x}(y) \\
\varepsilon_{y}(y) & -\varepsilon_{x}(y) & 1
\end{array}\right] \\
& +\left[\left[\begin{array}{c}
\varepsilon_{x}(z) \\
\varepsilon_{y}(z)-z \alpha_{y z} \\
z+\varepsilon_{z}(z)
\end{array}\right]\right. \\
& +\left[\begin{array}{ccc}
1 & \varepsilon_{z}(z) & -\varepsilon_{y}(z) \\
-\varepsilon_{z}(z) & 1 & \varepsilon_{x}(z) \\
\varepsilon_{y}(z) & -\varepsilon_{x}(z) & 1
\end{array}\right]\left(\left[\begin{array}{c}
x+\varepsilon_{x}(x) \\
\varepsilon_{y}(x)-y \alpha_{x y} \\
\varepsilon_{z}(x)-z \alpha_{x z}
\end{array}\right]\right. \\
& \left.\left.+\left[\begin{array}{ccc}
1 & \varepsilon_{z}(x) & -\varepsilon_{y}(x) \\
-\varepsilon_{z}(x) & 1 & \varepsilon_{x}(x) \\
\varepsilon_{y}(x) & -\varepsilon_{x}(x) & 1
\end{array}\right]\left[\begin{array}{l}
x_{m} \\
y_{m} \\
z_{m}
\end{array}\right]\right)\right] \\
& +\left[\begin{array}{l}
\delta_{x}(x, z), \varepsilon_{x}(x, z) \\
\delta_{y}(y, z), \varepsilon_{y}(y, z) \\
\delta_{z}(x, z), \delta_{z}(y, z)
\end{array}\right]
\end{aligned}
$$

In the above equation, the three actual coordinates of $\mathrm{ON}$ are $X_{n}, Y_{n}$, and $Z_{n}$, and the theoretical coordinates of point $\mathrm{N}$ of the measuring head are $\left(\mathrm{x}+\mathrm{x}_{\mathrm{m}}, \mathrm{y}+\mathrm{y}_{\mathrm{m}}, \mathrm{z}+\mathrm{z}_{\mathrm{m}}\right)$. Then the systematic error can be obtained as follows:

$$
\begin{aligned}
& \Delta x=x_{n}-\left(x+x_{m}\right) \\
& \Delta y=y_{n}-\left(y+y_{m}\right) \\
& \Delta z=z_{n}-\left(z+z_{m}\right)
\end{aligned}
$$

From (16) and (17), it can be derived that the positioning errors of the measuring head in $\mathrm{X}, \mathrm{Y}$, and $\mathrm{Z}$ directions are obtained by the nonlinear influence of the motion errors, deformation errors, and other uncertain errors of the measuring machine in the three directions. In the actual process, different deformation by different actions and influences by random factors arise at different positions due to the fact that the system is not an ideal rigid body and that the component structure is complex. Therefore, there are problems such as limited model theory, poor versatility, complex modeling, long time, low robustness, and unsuitability for real-time compensation for errors [23]. Consequently, this paper proposes the optimized algorithm backpropagation neural network (OA-BPNN) adaptive compensation method for mechanical structure error of the blade measuring system. The error value predicted by the OA-BPNN algorithm is utilized as the error compensation amount of the blade measuring system, which can effectively improve the measurement accuracy and error compensation rate.

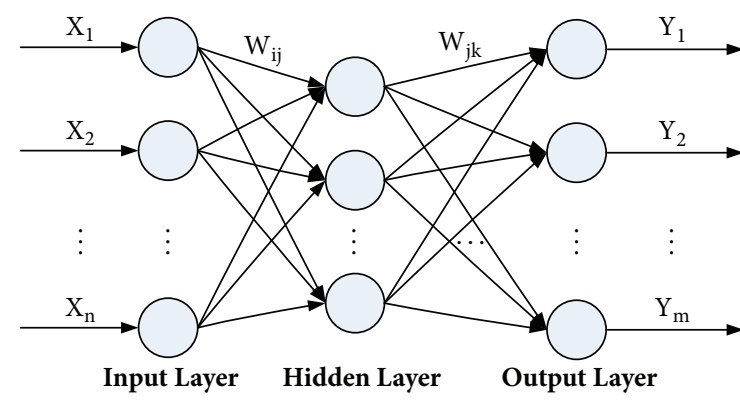

FIgURE 3: Topology of the BP neural network.

\section{Design of the Backpropagation (BP) Neural Network Compensation Algorithm}

3.1. BP Neural Network. The BP neural network is a multilayer feedforward neural network, which features forward propagation of signals and backpropagation of errors. In the forward propagation, the input signals are passed layer by layer from the input layer via the hidden layer to the output layer. The neuronal state of each layer only affects the state of neurons of the next layer. If the output layer does not obtain the expected outputs, then it goes into the back propagation and adjusts the network weights and thresholds based on the predicted error so that the predicted values by the BP neural network continuously approaches the expected outputs. The topology of the BP neural network is shown in Figure 3 and it can be regarded as a nonlinear function. The network input values and predicted values are the independent and dependent variables of the function. When the number of input nodes is $\mathrm{n}$ and the number of output nodes is $\mathrm{m}$, the BP neural network expresses the function mapping relationship from $\mathrm{n}$ independent variables to $\mathrm{m}$ dependent variables[24].

3.2. Optimized Algorithm Backpropagation Neural Network (OA-BPNN) Compensation Algorithm. The structure of the error prediction model for the blade measuring system constructed in this paper is shown in Figure 4, according to the characteristics of the errors in the previous section. It has one input layer node, two hidden layers that both has 5 nodes, and one output layer node. $X$ is the input value, that is, the node of the error measurement. $W_{0 \mathrm{i}}$ is the weight from the input layer to the hidden layer. $W_{\mathrm{ij}}$ is the weight from one hidden layer to the other hidden layer. $W_{\mathrm{j} 3}$ is the weight from the hidden layer to the output layer. $Y$ is the output value of the BP neural network, that is, the predicted value of the measurement error.

Based on the above structural relationship in Figure 4, (18) and (19) are used to express the propagation and weights in the BP neural network.

$$
\begin{aligned}
& H_{i}=f\left(w_{0 i} x+a_{i}\right) \quad i=1,2, \ldots, 5 \\
& H_{j}=f\left(\sum_{i=1}^{5} w_{i j} H_{i}+a_{j}\right) \quad j=1,2, \ldots, 5,
\end{aligned}
$$




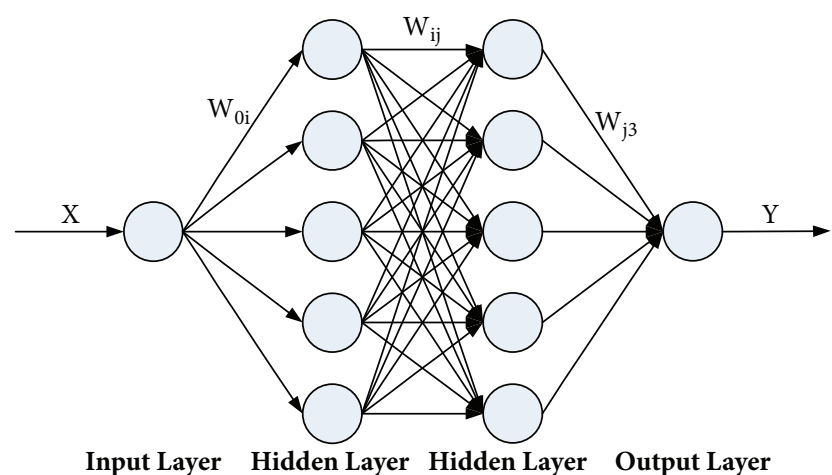

FIGURE 4: Structure of the OA-BPNN error prediction model.

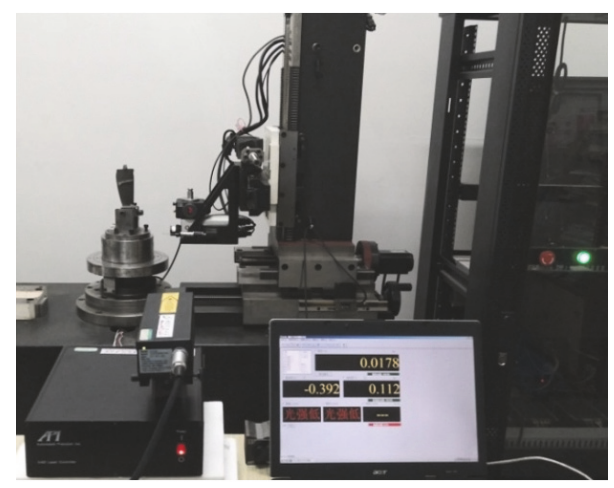

Figure 5: Experiment system.

where $f$ is the activation function of the hidden layer, which has a variety of expressions. The function chosen in this paper is the unipolar Sigmoid function.

$$
f(x)=\frac{1}{1+e^{-x}}
$$

Based on the output $H$ of the hidden layer, the weight $w_{j 3}$ and threshold $a_{3}$ are used to calculated the predicted output $O$.

$$
O=\sum_{j=1}^{5} H_{j} w_{j 3}+a_{3}
$$

The function chosen for the activation function of the output layer is the Purelin function $g(x)=x$, so the input of the output layer is equal to the output. According to the network predicted output $O$ and the expected output $Y$, the network predicted error e is calculated and the predicted error is calculated using the square sum error function.

$$
\begin{aligned}
e & =Y-O \\
E & =\frac{1}{2} e^{2}
\end{aligned}
$$

Then the weights and thresholds of the network are continuously adjusted by backpropagation, and finally the global error coefficient is minimized. The network connection weights $w_{0 i}, w_{i j}, w_{j 3}$ are updated according to the network predicted error $e_{i}$, and the learning rate is $\gamma$, as shown in the following.

$$
\begin{aligned}
w_{0 i}=w_{0 i}+\gamma \frac{\partial E}{\partial w_{0 i}} \quad i=1,2, \ldots, 5 ; \\
w_{i j}=w_{i j}+\gamma \frac{\partial E}{\partial w_{i j}} \quad i=1,2, \ldots, 5 ; j=1,2, \ldots, 5 ; \\
w_{j 3}=w_{j 3}+\gamma \frac{\partial E}{\partial w_{j 3}} \quad j=1,2, \ldots, 5 ;
\end{aligned}
$$

In the process of error backpropagation, the goal is to obtain the minimum value of the error function, namely, $\min E$, so the gradient descent method is used to calculate it. In (25), $\partial E / \partial w_{i j}$ is calculated as follows, and it is calculated in the same way in (24) and (26).

$$
\begin{aligned}
& \frac{\partial E}{\partial w_{i j}}=\frac{\partial E}{\partial H_{j}} \times \frac{\partial H_{j}}{\partial w_{i j}} \\
& \frac{\partial E}{\partial H_{j}}=(Y-O) \frac{\partial O}{\partial H_{j}}=-w_{j 3} e \\
& \frac{\partial H_{j}}{\partial w_{i j}}=\frac{\partial f\left(\sum_{i=1}^{5} w_{i j} H_{i}+a_{j}\right)}{\partial w_{i j}}=H_{j}\left(1-H_{j}\right) H_{i} \\
& w_{i j} \text { is updated as equation }(28): \\
& w_{i j}=w_{i j}+\gamma H_{j}\left(1-H_{j}\right) H_{i} w_{j 3} e \quad i, j=1,2, \ldots, 5 ;
\end{aligned}
$$

Thresholds and weights are updated in a similar way. The network node thresholds $a_{i}, a_{j}, a_{3}$ and learning rate $\gamma$ are updated according to the network predicted error $e$.

$$
\begin{aligned}
& a_{i}=a_{i}+\gamma \frac{\partial E}{\partial a_{i}} \quad i=1,2, \ldots, 5 \\
& a_{j}=a_{j}+\gamma \frac{\partial E}{\partial a_{j}} \quad j=1,2, \ldots, 5 \\
& a_{3}=a_{3}+\gamma \frac{\partial E}{\partial a_{3}}
\end{aligned}
$$

In (30), $\partial E / \partial a_{j}$ is calculated as follows, and (29) and (31) are calculated in the same way.

$$
\begin{aligned}
& \frac{\partial E}{\partial a_{j}}=\frac{\partial E}{\partial H_{j}} \times \frac{\partial H_{j}}{\partial a_{j}} \\
& \frac{\partial E}{\partial H_{j}}=(Y-O) \frac{\partial O}{\partial H_{j}}=-w_{j 3} e \\
& \frac{\partial H_{j}}{\partial a_{j}}=\frac{\partial f\left(\sum_{i=1}^{5} w_{i j} H_{i}+a_{j}\right)}{\partial a_{j}}=H_{j}\left(1-H_{j}\right)
\end{aligned}
$$

The final updated equation for $a_{j}$ is

$$
a_{j}=a_{j}+\gamma H_{j}\left(1-H_{j}\right) w_{j 3} e \quad j=1,2, \ldots, 5
$$




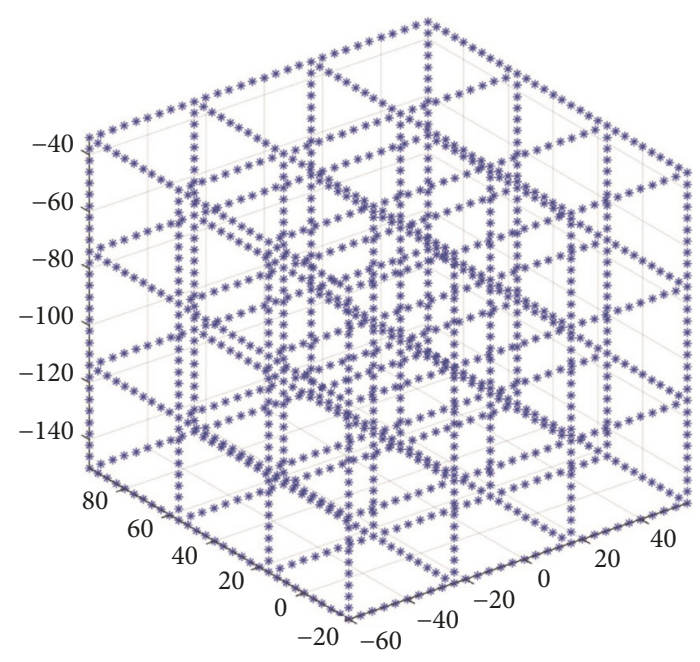

FIGURE 6: Cloud of the measurement spatial nodes.

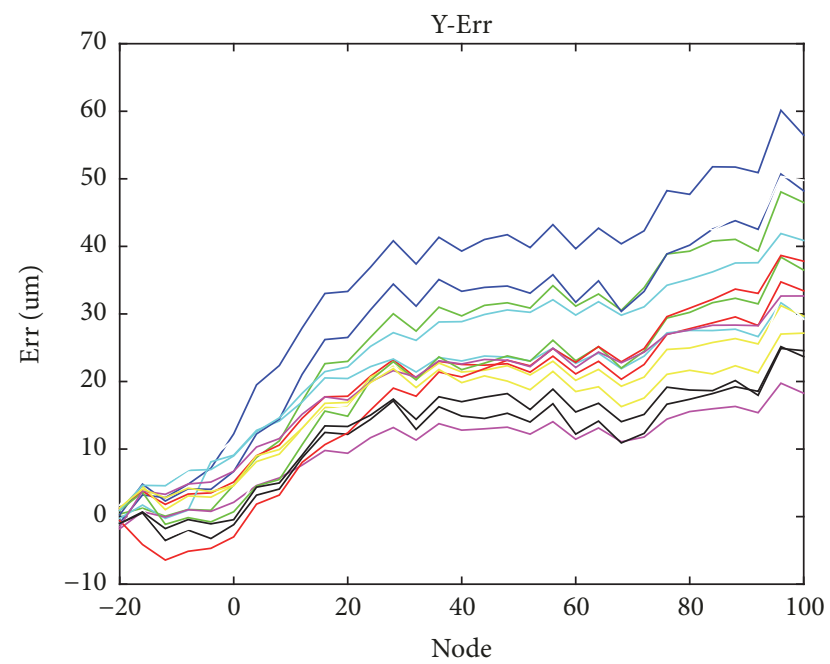

FIGURE 7: Error distribution in the Y direction.

Finally, its convergence is based on whether the adjacent two errors are smaller than the specified value. If it converges, the output of the first hidden layer is recalculated until the requirement is satisfied.

\section{Error Compensation Experiment}

4.1. Design of the Experiment. In this experiment, shown in Figure 5, a laser interferometer is used to measure and verify the spatial nodes error of the mechanical structure of the measurement system. The laser interferometer is characterized by high precision, the linear resolution of up to $0.02 \mu \mathrm{m}$, and large measuring range and can perform continuous measurement, so it is widely used in error measurement of machine tools or measuring machines [25]. The measurement accuracy in the experiment is related to the parameters of the surrounding environment, including air temperature, air pressure, and relative humidity [26]. Therefore, the matching devices of the laser interferometer, such as air temperature sensor, air pressure sensor, and relative humidity sensor, should be input to the socket of the host of the laser transmitter, and the relevant compensation coefficients in the measurement software should be set. The three-direction movement range of the measurement mechanism constitutes a measurement space, where the error differs in different directions and at different positions [27]. Therefore, the entire space is divided in this paper. Each direction is evenly divided by 30 selected points spaced $4 \mathrm{~mm}$ apart. The measurement spatial nodes are shown in Figure 6.

In the experiment, the three-dimensional coordinate error of each node in the space can be measured. Figure 7 shows the error of each nodes on the 16 lines in the $\mathrm{Y}$ direction, with the maximum being $60.1 \mu \mathrm{m}$.

4.2. Data Processing and Comparison Analysis. After the measurement, linear error and nonlinear error are included in the data. The linear error can be corrected. However, it is hard to attain a standard model to compensate for the nonlinear error. The least square polynomial fitting, genetic algorithm BP neural network (GA-BPNN) algorithm, and the OA-BPNN algorithm are adopted to fit the systematic error data of the mechanical structure and the fitting results are compared.

For the $\mathrm{X}$ direction, three algorithms are used for error data fitting and comparison. As shown in Figure 8, graphs (a), (b), and (c) are the error data fittings and residual plots of the three algorithms, respectively. Graph (d) is the residual comparison of the three fitting methods. It can be seen that the proposed OA-BPNN fitting error is completely consistent with the curve trends of other methods.

For the Y direction, three algorithms are used for error data fitting and comparison. As shown in Figure 9, graphs (a), (b), and (c) are the error data fittings and residual plots of the three algorithms, respectively. Graph (d) is the residual comparison of the three fitting methods. It can be seen that the proposed OA-BPNN fitting error is completely consistent with the curve trends of other methods.

For the $\mathrm{Z}$ direction, three algorithms are used for error data fitting and comparison. As shown in Figure 10, graphs (a), (b), and (c) are the error data fittings and residual plots of the three algorithms, respectively. Graph (d) is the residual comparison of the three fitting methods. It can be seen that the proposed OA-BPNN fitting error is completely consistent with the curve trends of other methods.

It can be seen from Figures 8, 9, and 10 that when the error term in each direction is the minimum in the least square polynomial fitting, the $\mathrm{X}$ direction fits to a 6th-order polynomial fitting, the $\mathrm{Y}$ direction fits to a 5th-order polynomial fitting, and the $\mathrm{Z}$ direction fits to a 4 th-order polynomial fitting. The GA-BPNN algorithm and the proposed OABPNN algorithm are adaptive to different error data fittings. The trends of the three fitting methods are basically the same, and there is no significant difference in accuracy.

4.3. Analysis of the Error Compensation Results. The polynomial fitting, proposed OA-BPNN, and GA-BPNN compensation algorithms are used to compensate for errors in the $\mathrm{XYZ}$ directions. Ten experiments are performed and the results are 

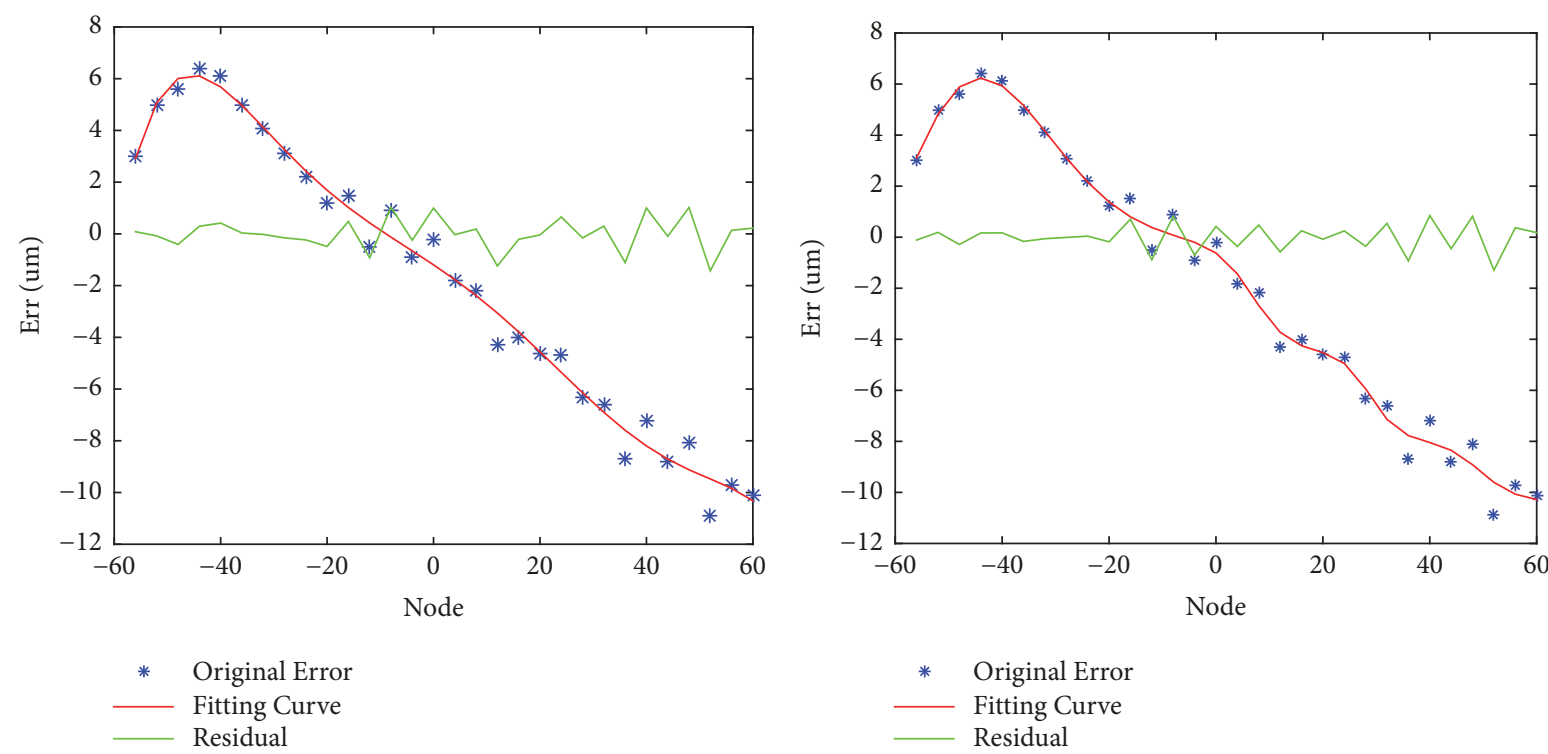

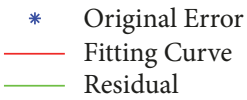

(a) Sixth-order polynomial fitting results

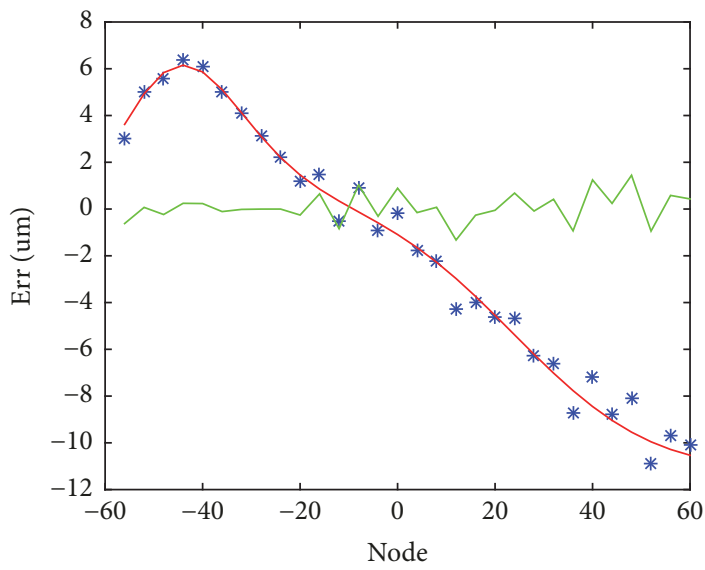

* Original Error Fitting Curve Residual

(c) GA-BPNN fitting results (b) OA-BPNN fitting results

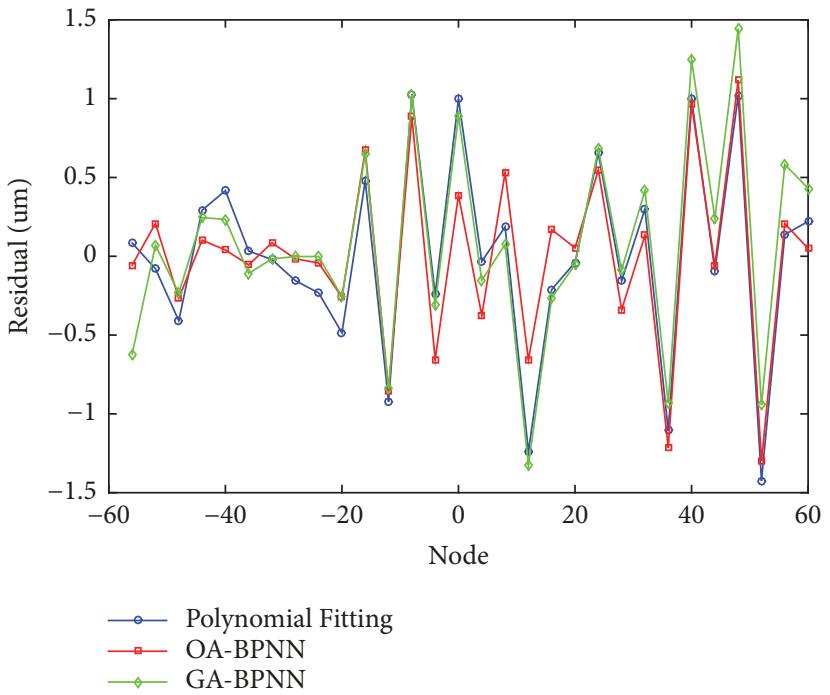

(d) Residual graph of the three fitting methods

FIGURE 8: Data fitting comparison in the $\mathrm{X}$ direction.

TABLE 1: Compensation results in the $\mathrm{X}$ direction.

\begin{tabular}{lccc}
\hline $\mathrm{X}$ & $\begin{array}{c}\text { Sixth-order } \\
\text { Polynomial Fitting }\end{array}$ & OA-BPNN & GA-BPNN \\
\hline Time $(s)$ & $\mathbf{0 . 2}$ & 1.1 & 60.8 \\
MAE $(\mu \mathrm{m})$ & 1.4 & $\mathbf{1 . 3}$ & 1.4 \\
$\operatorname{MSE}(\mu \mathrm{m})$ & 0.4 & $\mathbf{0 . 3}$ & 0.4 \\
\hline
\end{tabular}

shown in Tables 1,2, and 3. Although the maximum absolute errors and mean square errors by the three algorithms are almost the same, the GA-BPNN fitting takes too long and the polynomial fitting is not an adaptive error compensation method because the best fitting high-order terms should
TABLE 2: Compensation results in the $\mathrm{Y}$ direction.

\begin{tabular}{lccc}
\hline Y & $\begin{array}{c}\text { fifth-order } \\
\text { Polynomial Fitting }\end{array}$ & OA-BPNN & GA-BPNN \\
\hline Time $(s)$ & $\mathbf{0 . 2}$ & 1.3 & 61.6 \\
MAE $(\mu \mathrm{m})$ & 4.1 & $\mathbf{4 . 0}$ & 4.1 \\
$\operatorname{MSE}(\mu \mathrm{m})$ & 2.8 & $\mathbf{2 . 5}$ & 2.8 \\
\hline
\end{tabular}

be determined in the polynomial fitting, which depends on personnel experience.

In summary, the OA-BPNN algorithm used in this paper is characterized by the best adaptability, precision, and efficiency for the adaptive error compensation. The maximum errors (MAE) in the XYZ directions are reduced by $88.1 \%$, 

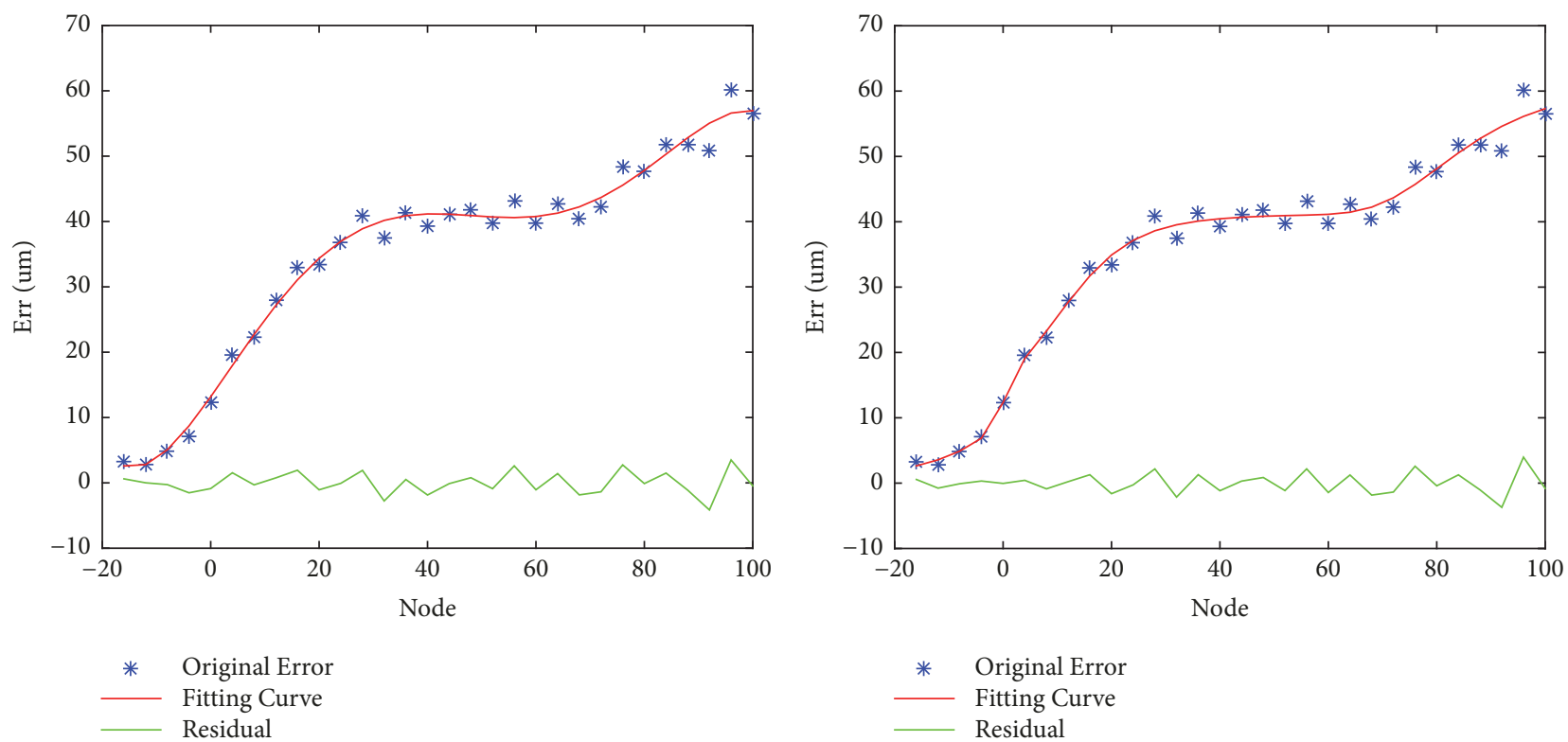

(b) OA-BPNN fitting results
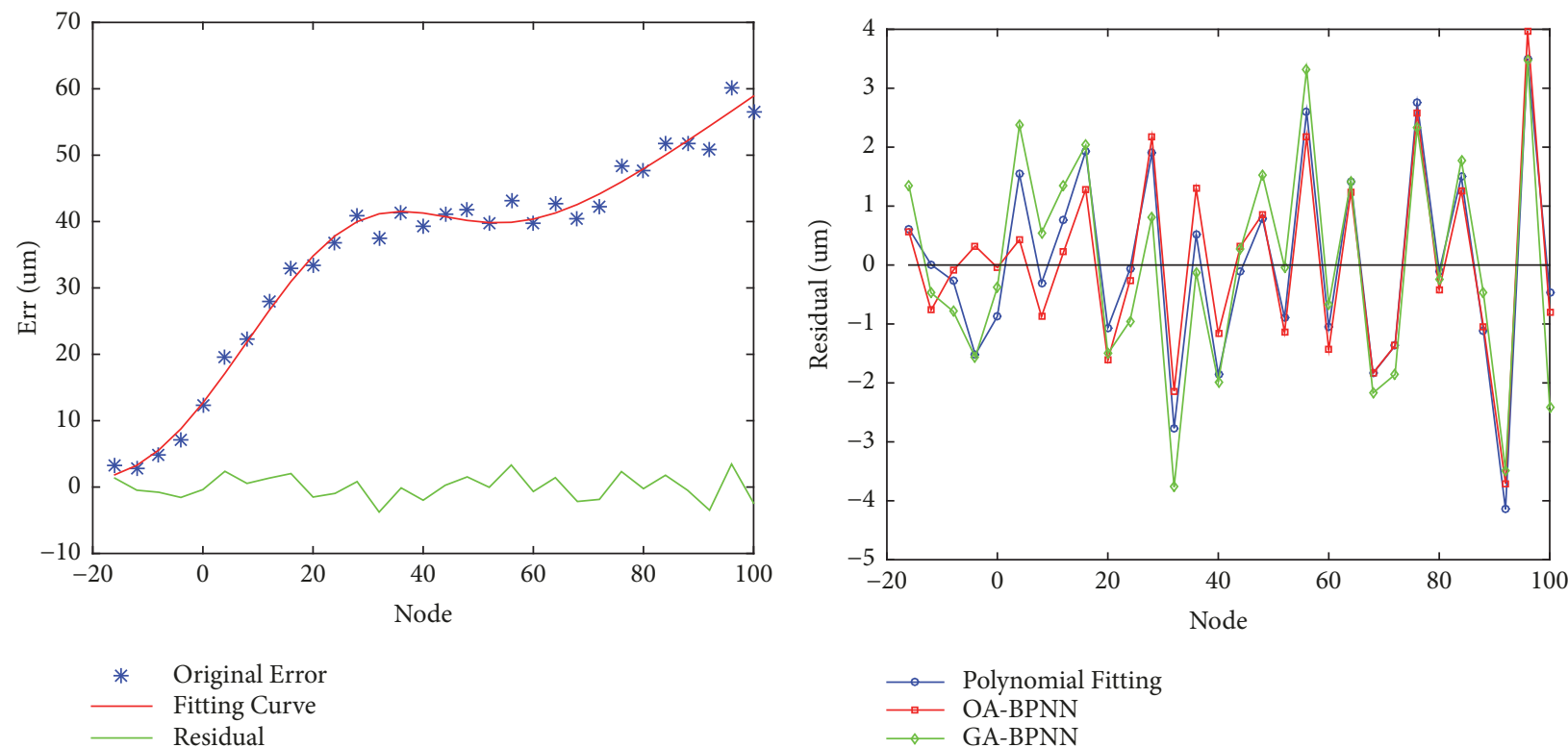

c) GA-BPNN fitting results

(d) Residual graph of the three fitting methods

FIgURE 9: Data fitting comparison in the Y direction.

TABLE 3: Compensation results in the $\mathrm{Z}$ direction.

\begin{tabular}{lccc}
\hline Z & $\begin{array}{c}\text { fourth-order } \\
\text { Polynomial Fitting }\end{array}$ & OA-BPNN & GA-BPNN \\
\hline Time $(s)$ & $\mathbf{0 . 2}$ & 1.1 & 61.3 \\
MAE $(\mu m)$ & $\mathbf{2 . 4}$ & 2.4 & 2.5 \\
$\operatorname{MSE}(\mu \mathrm{m})$ & 1.6 & $\mathbf{1 . 5}$ & 1.8 \\
\hline
\end{tabular}

93.7\%, and $97.2 \%$, from $10.9,60.1$, and $84.2 \mu m$ to $1.3,4.0$, and $2.4 \mu \mathrm{m}$, respectively. Mean square error (MSE) is similar.

\section{Conclusions}

In order to compensate for the error in the blade measuring system, this paper proposes a laser interferometer to measure the error of the spatial nodes of the measurement system based on the findings of previous studies. The OA-BPNN compensation method is utilized to adaptively compensates for the systematic error of the mechanical system. Compared with the traditional polynomial fitting and genetic BP neural network (GA-BPNN) algorithm, the results show that the optimized backpropagation neural network (OA-BPNN) algorithm is characterized by the best adaptability, precision, 


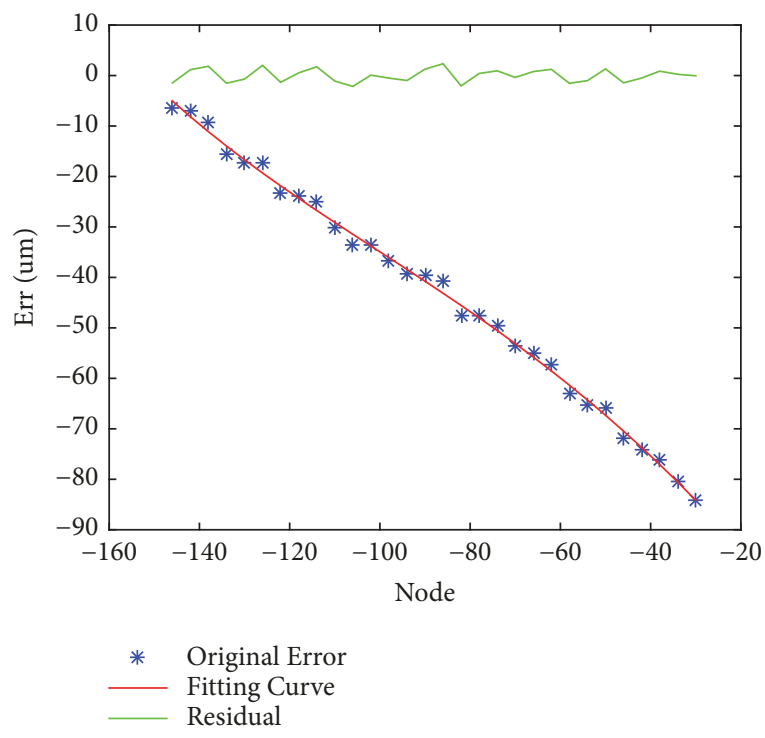

(a) Fourth-order polynomial fitting results

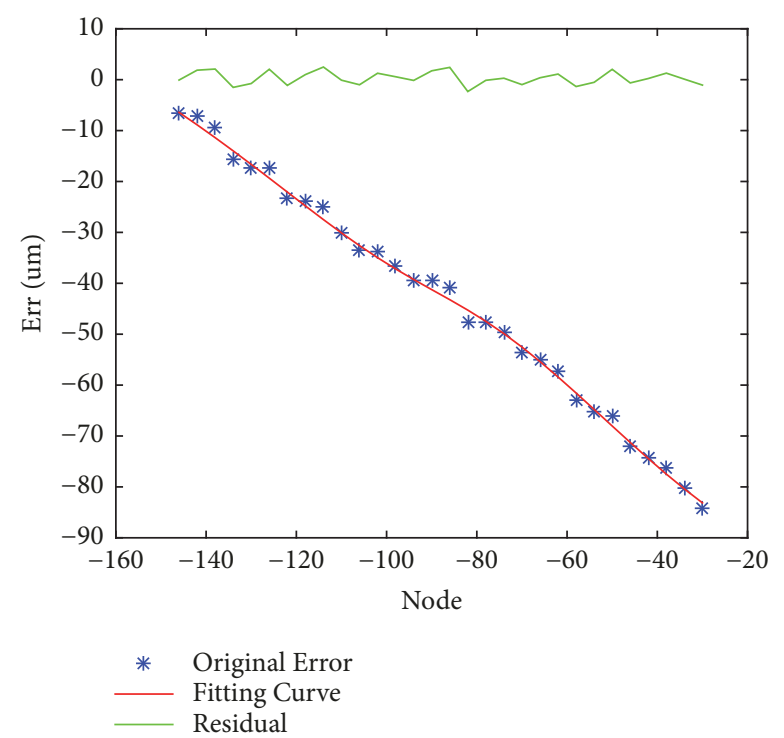

(c) GA-BPNN fitting results

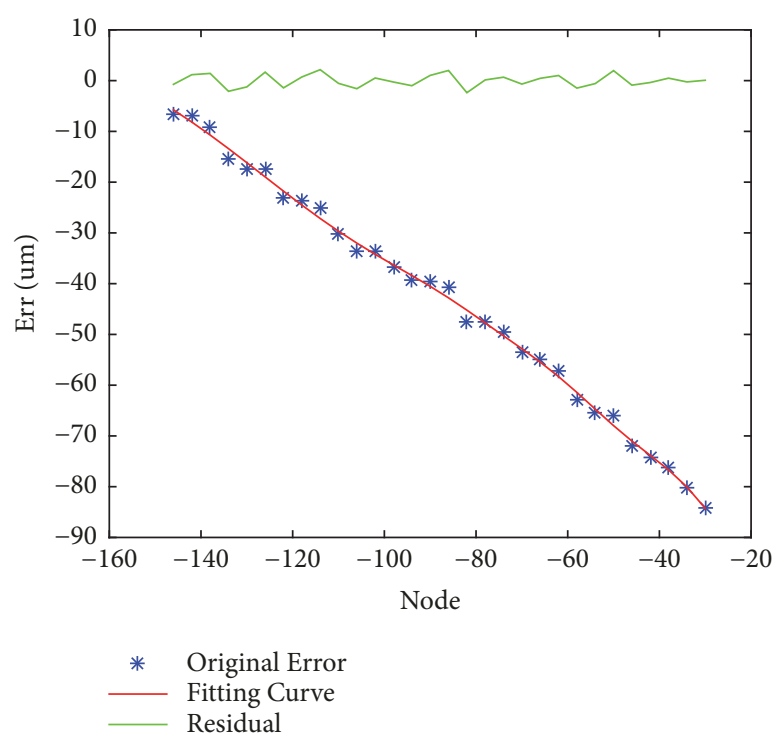

(b) OA-BPNN fitting results

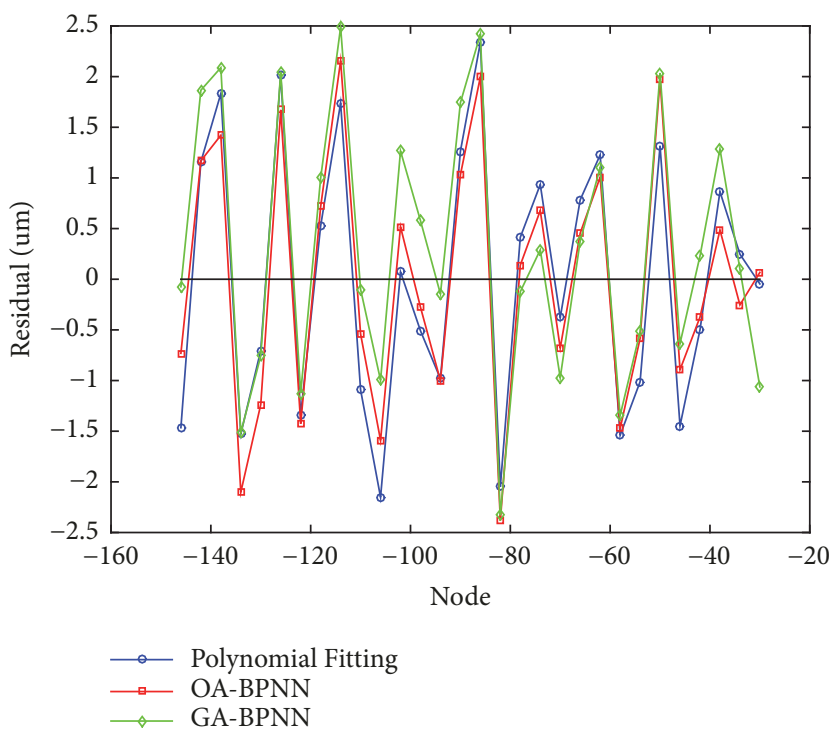

(d) Residual graph of the three fitting methods

FIgURE 10: Data fitting comparison in the $\mathrm{Z}$ direction.

and efficiency for the self-adaptive error compensation. The maximum errors in the XYZ directions are reduced by $88.1 \%$, $93.7 \%$, and $97.2 \%$, from $10.9,60.1$, and $84.2 \mu \mathrm{m}$ to $1.3,4.0$, and $2.4 \mu \mathrm{m}$, respectively. The method is of great theoretical significance and practical value for error compensation of other measuring systems.

\section{Data Availability}

The data used to support the findings of this study are available from the corresponding author upon request.

\section{Conflicts of Interest}

The authors declare that they have no conflicts of interest.

\section{Acknowledgments}

This work was supported by the National Natural Science Foundation of China (NSFC) under Grants nos. 51775433 and 51505359.

\section{References}

[1] X. Z. Zheng, S. K. Tao, and X. Q. Huang, "Blade profile, data analysis and error assessment study method," Aviation Precision Manufacturing Technology, vol. 50, no. 4, pp. 24-26, 2014.

[2] C. Bi, J. G. Fang, T. T. Song et al., "Establishment of optical measuring system for blades edges," Optics and Precision Engineering, vol. 25, no. 10, pp. 2744-2751, 2017. 
[3] X. Q. Shi, B. H. Wu, and D. H. Zhang, "Development Tendency of Inspecting Technology for Aeroengine Blade," Aeronautical Manufacturing Technology, vol. 481, no. 12, pp. 80-84, 2015.

[4] X. Li, Z. Shi, H. Chen, and J. Lin, "Current status and trends of aeroengine blade profile metrology," Journal of Beijing University of Technology, vol. 43, no. 4, pp. 557-565, 2017.

[5] Z. Huang, C. Li, and K. Li, "Status and prospect of detection technology of coordinate measuring machine for blade surface of aeroengine," Aeronautical Manufacturing Technology, vol. 60, no. 21, pp. 73-79, 2017.

[6] C. S. Dong, J. Qu, and J. X. Wang, "Description of motion accuracy of the 3-D coordinate measuring machine," Aviation Precision Manufacturing Technology, vol. 34, no. 1, pp. 32-34, 1998.

[7] H. Wei, W. Wang, L. Pei, and Q. Zheng, "Geometric error compensation of coordinate measurement machine with step gauge," Chinese Journal of Scientific Instrument, vol. 31, no. 10, pp. 2374-2380, 2010.

[8] X. L. Nian, Research on Structural Design and Error Analysis of Mobile Bridge Coordinate Measuring Machines, Harbin University of Science and Technology, 2012.

[9] W. W. Qu, F. Gao, F. R. Du et al., "Error source analysis and modification technology of three coordinates measuring machine," Journal of Machine Design, vol. 26, no. 6, pp. 76-78, 2009.

[10] Q. D. Yang, C. Van Den, and P. Bergh, “The Thermal Deformations and Error Compensation Based on Neural Network on a CMM," Acta Metrologica Sinica, vol. 21, no. 2, pp. 113-118, 2000.

[11] H. W. Xu, G. P. Zhuang, Y. M. Huang et al., "Study on influences of marble machine tool bed on distribution of temperature fields of the headstock," China Mechanical Engineering, vol. 22, no. 11, pp. 1274-1277, 2011.

[12] Y. Lu, Y. Qu, Z. Luo et al., "Analysis and modeling of dynamic error compensation of CMM," China Mechanical Engineering, vol. 22, no. 2, pp. 144-147, 2011.

[13] A. Zhou, W. Shao, and Y. Wu, "A new method of aviation blade measurement via applications of conoscopic holography principle," China Mechanical Engineering, vol. 28, no. 12, pp. 1394-1399, 2017.

[14] G. Zhang, R. Veale, T. Charlton, B. Borchardt, and R. Hocken, "Error compensation of coordinate measuring machines," CIRP Annals - Manufacturing Technology, vol. 34, no. 1, pp. 445-448, 1985.

[15] J. Guo, L. Zhang, and B. Pi, "Method of spatial error detecting and 21 items geometrical error separating for CMM," China Mechanical Engineering, vol. 13, no. 13, p. 1081, 2002.

[16] S. W. Lin, Z. T. Wu, and G. Li, "Volumetric distribution feature of measuring coordinate errors integrating with nonrigid errors," Chinese Journal of Scientific Instrument, vol. 22, no. 2, pp. 172-175, 2001.

[17] K. C. Song, Y. Q. Zhang, and S. H. Li, "A study of compensation for dynamic errors of CMMS," Chinese Journal of Scientific Instrument, vol. 20, no. 1, pp. 23-25, 1999.

[18] Y. T. Fei, J. Zhao, H. T. Wang et al., "A Review of Research on Dynamic Errors of Coordinate Measuring Machines," Chinese Journal of Scientific Instrument, vol. 25, no. zl, pp. 773-776, 2004.

[19] A. Gąska, J. Sładek, K. Ostrowska et al., "Analysis of changes in coordinate measuring machines accuracy made by different nodes density in geometrical errors correction matrix," Measurement, vol. 68, pp. 155-163, 2015.
[20] T. Q. Gu, J. X. Chen, J. W. Huang et al., "Study on the linear regression method for straightness error of coordinate measuring machine," Journal of Fuzhou University (Natural Science Edition), vol. 45, no. 6, pp. 881-884, 2017.

[21] H. F. Chen, B. W. Zhen, Z. Y. Shi et al., "CMM spatial coordinate correction method based on laser tracer multistation measurement," Chinese Journal of Lasers, vol. 44, no. 3, Article ID 0304003, 2017.

[22] C. C. Wang, Y. T. Fei, W. T. Chen et al., "Designing of Cantilever Type CMM and Error Compensation," Tool Engineering, vol. 44, no. 1, pp. 98-101, 2010.

[23] H. Wang, J. Wang, Q. Zhou, Q. Xiong, and Z. Wei, "Comprehensive Error Compensation of Machine Tools Based on BP-Neural Network Algorithm," Journal of Xian Jiaotong University, vol. 51, no. 6, pp. 138-146, 2017.

[24] X. C. Wang, F. Shi, and L. Yu, MATLAB Neural Network 43 Case Analysis, Beihang University Press, Beihang, China, 2013.

[25] H. Lee, K. Huang, H. Peng, and C. Liu, "A real time error measuring device for meso-scale machine tools," Sensors and Actuators A: Physical, vol. 244, pp. 213-222, 2016.

[26] J. H. Zhuang, "Application of Laser Interferometer in Improving Accuracy of CNC Machine Tool," Machine Tool and Hydraulics, vol. 39, no. 4, pp. 114-115, 2011.

[27] J. X. Chen, S. W. Liu, and X. L. Zhou, "A comprehensive error analysis method for the geometric error of multi-axis machine tool," International Journal of Machine Tools \& Manufacture, vol. 106 , pp. 56-66. 


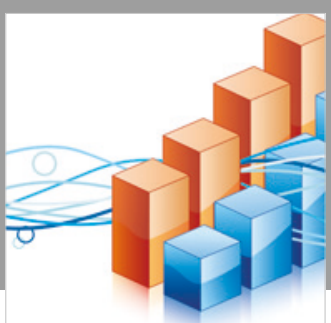

Advances in

Operations Research

\section{-n-m}
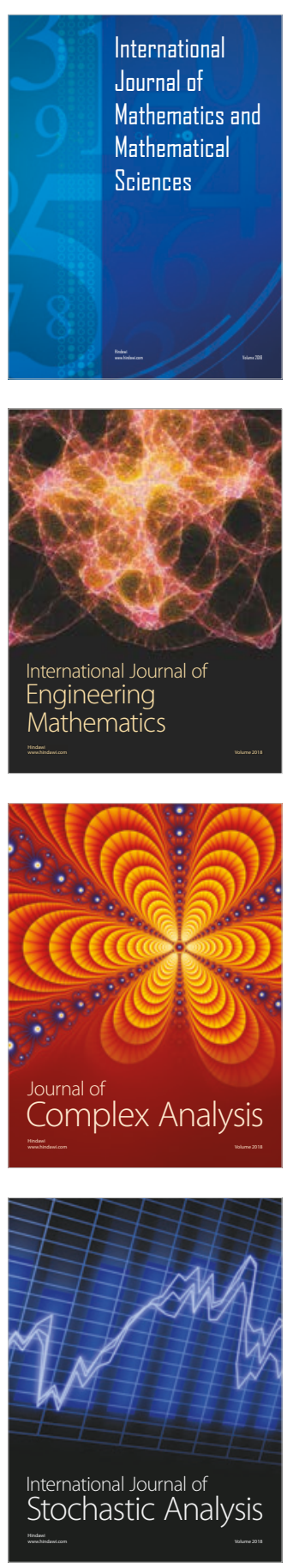
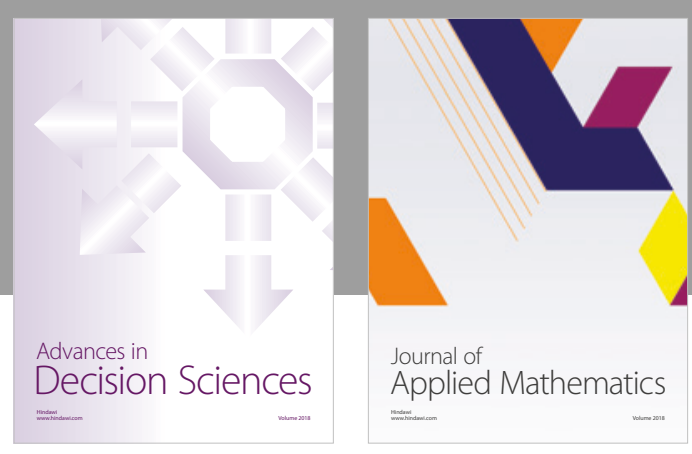

Journal of

Applied Mathematics
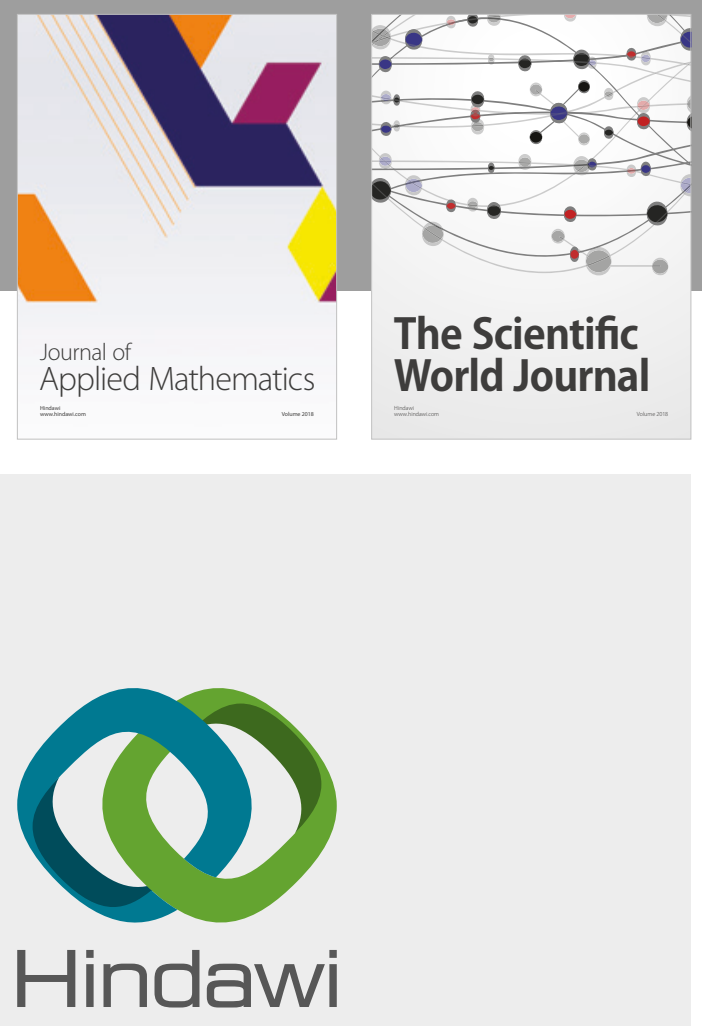

Submit your manuscripts at

www.hindawi.com

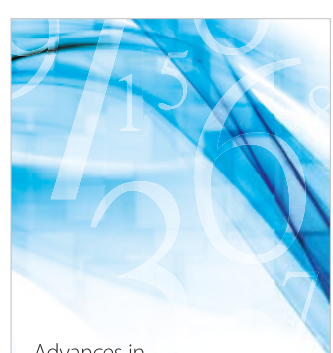

Advances in
Numerical Analysis
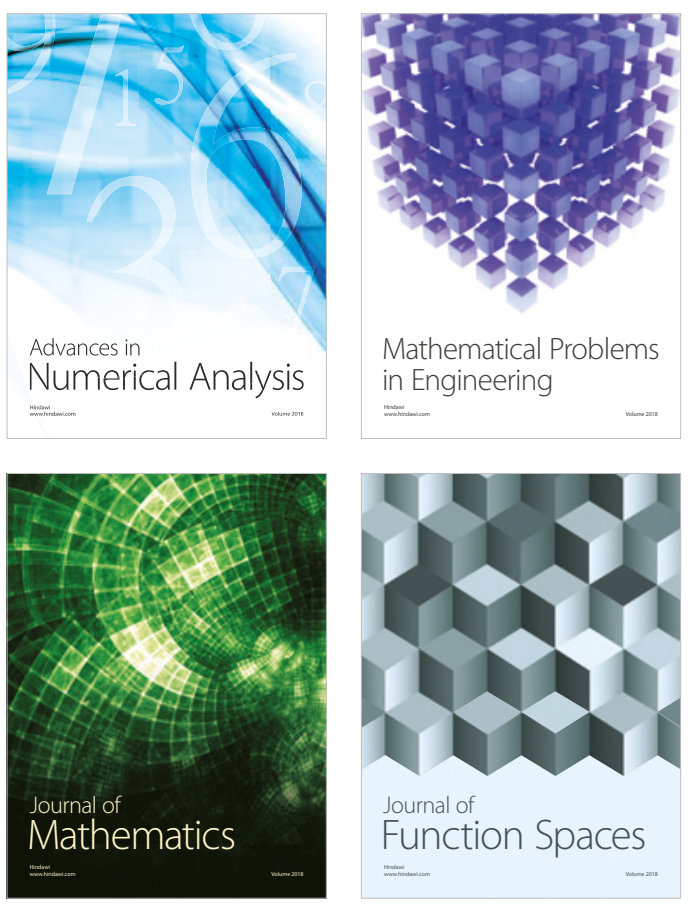

Mathematical Problems in Engineering

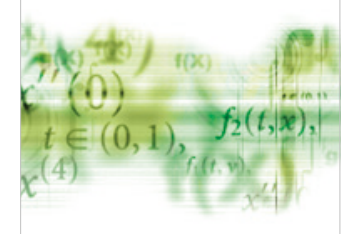

International Journal of

Differential Equations

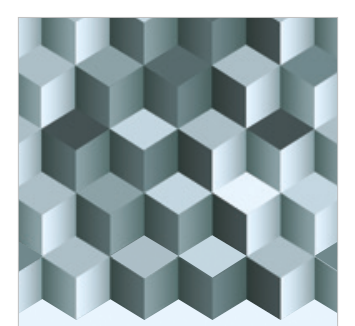

Journal of

Function Spaces
The Scientific

World Journal

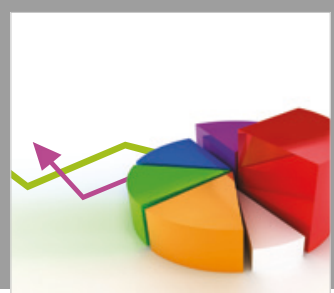

Journal of

Probability and Statistics
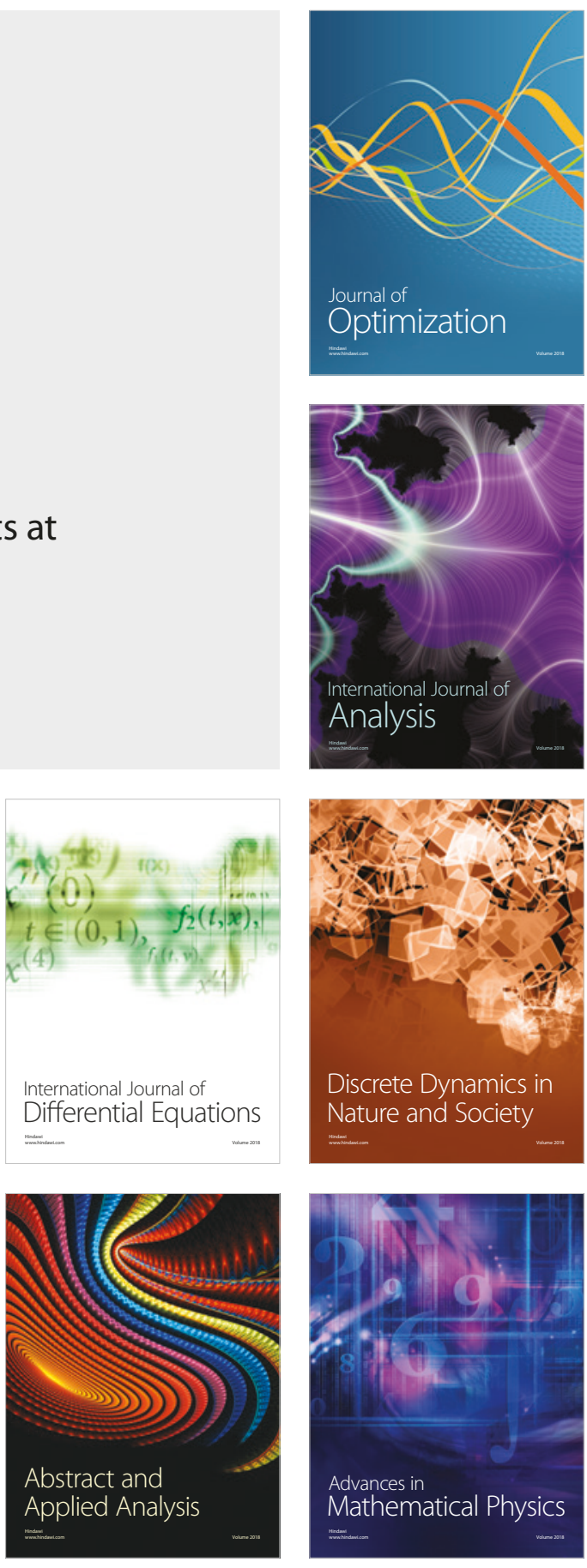